\title{
Compulsory Citizenship Behavior leads to Counterproductive Work Behavior
}

\author{
$\mathrm{Li} \mathrm{Su}$ \\ CAS Key Laboratory of Behavioral \\ Science, Institute of Psychology, \\ Beijing 100101, China, Department of \\ Psychology, University of Chinese \\ Academy of Sciences, Beijing 100049 \\ China \\ 5911417@qq.com
}

\author{
A Multiple Mediation Path
}

\author{
Yiwen Chen \\ CAS Key Laboratory of Behavioral \\ Science, Institute of Psychology, \\ Beijing 100101, China, Department of \\ Psychology, University of Chinese \\ Academy of Sciences, Beijing 100049 \\ China \\ Chenyw@psych.ac.cn
}

\author{
Yiping Li \\ Yangzhou Perfect Co.,Ltd., Yangzhou \\ 225027, China \\ liyp@perfect99.com
}

\begin{abstract}
Based on the theory of social exchange and the theory of conservation of resources, this research discusses the mechanism between compulsory citizenship behavior and counterproductive behavior, and studies the roles of emotional exhaustion, moral disengagement and employee silence in the relationship between them. Based on the effective sample data of 525 employees in manufacturing enterprises, structural equation model and Bootstrap method were used to test the sample data. The results show that there is a significant positive correlation between compulsory citizenship behavior and counterproductive behavior. Emotional exhaustion, moral disengagement and employee silence played a chain mediating role in the relationship between the two.
\end{abstract}

\section{CCS CONCEPTS}

- Social and professional topics;

\section{KEYWORDS}

compulsory citizenship behavior, counterproductive work behavior, emotional exhaustion, moral disengagement, employee silence

ACM Reference Format:

$\mathrm{Li} \mathrm{Su}$, Yiwen Chen, and Yiping Li. 2021. Compulsory Citizenship Behavior leads to Counterproductive Work Behavior: A Multiple Mediation Path. In The 2021 12th International Conference on E-business, Management and Economics (ICEME 2021), July 17-19, 2021, Beijing, China. ACM, New York, NY, USA, 6 pages. https://doi.org/10.1145/3481127.3481191

\section{INTRODUCTION}

Organizational Citizenship Behavior (OCB) is defined as an individual Behavior that is freely determined by Organizational members and is not explicitly or directly recognized by the organization's formal salary system [1]. Organizational citizenship behavior can

Permission to make digital or hard copies of all or part of this work for personal or classroom use is granted without fee provided that copies are not made or distributed for profit or commercial advantage and that copies bear this notice and the full citation on the first page. Copyrights for components of this work owned by others than ACM must be honored. Abstracting with credit is permitted. To copy otherwise, or republish, to post on servers or to redistribute to lists, requires prior specific permission and/or a fee. Request permissions from permissions@acm.org.

ICEME 2021, fuly 17-19, 2021, Beijing, China

(C) 2021 Association for Computing Machinery.

ACM ISBN 978-1-4503-9006-4/21/07.. \$15.00

https://doi.org/10.1145/3481127.3481191 promote the effective operation of enterprises as a whole. But with the gradual deepening of the research, people are more and more deeply aware that not all soldiers have the motivation to be "good soldiers", there are many employees have the motivation and ability to be "good actors". Based on this change, Vigoda-Gadot redefined the boundary of organizational citizenship Behavior in 2006 and first proposed the concept of Compulsory Citizen Behavior (CCB), that is, the non-spontaneous citizenship Behavior of employees due to various social or management pressures within the organization [2].Compulsory citizenship behavior significantly exists in organizations, which not only significantly affects employees' work performance, but also increases their work pressure, enhances their intention to leave, and even leads to Counterproductive Workplace Behaviors (CWB) [3].As a typical behavior outside the negative role, counterproductive behavior will harm the legitimate interests of the organization or its members and cause the organization to suffer huge losses [4].

\section{THEORETICAL BACKGROUND}

\subsection{Compulsory citizenship Behavior and counterproductive work behavior}

The social exchange theory and the "stress-emotioncounterproductive behavior" model provide a good theoretical basis for the study of the relationship between compulsory citizenship behavior and counterproductive behavior.

According to social exchange theory, when employees for obvious instrumental motivation, hope to get support from your supervisor, the trust, the resources and opportunities such as good and sometimes had to engage in compulsory citizenship behavior, the staff would like to give the benefit of returns, so will be outside the scope of their duties to redouble its efforts, pour more resources into work. On the other hand, if your boss force employees to take on more of involuntary or beyond the scope of responsibility of work, employees often feel more pressure, so as to produce in the psychological imbalance, in order to realize a new equilibrium, then they are more inclined to take the relative countermeasures, such as such as didn't work hard, idle, are more likely to trigger a series of counterproductive behavior [6].

The "stress-emotion-counterproductive behavior" model proposed by Fox and Spector is also fully supported by a large number 
of empirical studies [7].The model regards emotion as the response center and counterproductive behavior as a response to work stress. According to this model, the involuntary nature of compulsory citizenship behavior can be regarded as a source of pressure in the work, which will cause the individual's sense of pressure, which will induce negative emotions and produce subsequent counterproductive behavior.

Therefore, this study believes that in the context of compulsory citizenship behavior, employees will feel more pressure, take negative extra-role behavior to deal with the pressure, and eventually lead to counterproductive behavior. Past research suggests something similar. Chinese scholar Zhao Hongdan et al. concluded that when employees are forced to perform more organizational citizenship behaviors, it may lead to the decline of job satisfaction and organizational identity, and present negative reactions and increase counterproductive behaviors. Bolino et al. believe that "good soldiers" who participate in organizational citizenship behavior may become "bad apples" because they feel great pressure and cause internal moral imbalance [8].Yam et al. also pointed out that citizenship under pressure may be the direct cause of counterproductive behaviors of employees [9].Therefore, the following hypotheses are made in this study:

Hypothesis1:Compulsory citizenship behavior has a significant positive correlation with counterproductive behavior.

\subsection{Mediating role of employee silence}

When employees are faced with coercive citizenship, must they immediately exhibit counterproductive behavior? What is the mechanism between the two? Studies have shown that when faced with compulsory citizenship behavior, employees tend to adopt relatively safe defensive behavior of withdrawal [10].In traditional Chinese culture, harmony, abiding by social norms and authority, and selfprotection are always emphasized values. Chinese people often say that "silence is golden" and "being cautious in words and deeds" all emphasize such values. In the cultural context of high collectivism and high power distance, employees' overreaction, direct counterattack and retaliation will be questioned as challenging authority. In order to avoid the deterioration of the relationship between superiors and subordinates, and at the same time to be afraid of becoming complainers or scoffers and being "overplayed" by supervisors, employees often take evasive or negative coping strategies, implement the defensive behavior of withdrawal, and choose the passive and implicit behavior of silence, which makes everything seem natural, logical and safe. When coercive citizenship becomes a source of pressure, silence behavior is an instinctive adaptive strategy used by Chinese employees in response to coercive citizenship behavior, which can play a certain buffer role.

According to the resource conservation theory, employees have limited resources to cope with work demands. When they feel the pressure brought by compulsory citizenship behavior, they will feel the crisis of resource depletion. At this time, employees tend to use silence to manage and preserve resources. At the same time, silence can also be seen as a behavioral indication that employees' need for control is not being met and thus give up expressing their thoughts and opinions. When silence depleting individual resources to cope with workplace demands, employees will try to get out of this state, such as by adopting counterproductive behavior, in order to preserve their resources. Therefore, this study makes the following hypothesis:

Hypothesis 2: Employee silence plays a mediating role in compulsory citizenship behavior and counterproductive behavior.

\subsection{The dual processing model of emotional exhaustion and moral disengagement}

Another important goal of this study is to demonstrate the mechanism between coercive citizenship behavior and employee silence. The performance of a behavior mainly comes from the two driving forces of emotion and cognition. The latest research on the relationship between compulsory citizenship behavior and employee silence behavior shows that emotional exhaustion and moral disengagement play an important role respectively $[11,12]$. Emotional exhaustion explains the process of employee silence behavior from the perspective of emotion. Moral disengagement, as a cognitive theory, explains the motivation of employee silence behavior from the cognitive perspective. This study will be integrated to build an "emotion-cognition" dual-processing model, so as to more comprehensively improve the mechanism between compulsory citizenship behavior and employee silence.

As a dimension of job burnout, emotional exhaustion refers to the physical and mental fatigue caused by the excessive use of psychological and emotional resources [13]. Compulsory citizenship behavior has a significant effect on emotional exhaustion. According to the theory of resource conservation, people always need to make efforts to preserve, protect and build resources. The "resources" here include tools, self-efficacy, time and energy, all kinds of resources that are always available to achieve individual goals. When not facing pressure, individuals actively seek to obtain additional resources to cope with future pressure by investing and accumulating more resources; When the resource investment fails to get sufficient return, the resource suffers loss or the resource is threatened with loss, the individual will experience psychological discomfort or pain; In the face of pressure, individuals will try to avoid further loss or consumption of resources, such as choosing to stay away from the source of pressure and taking a defensive posture to preserve the remaining resources [14].Compulsory citizenship will lead to the loss of employees' resources, resulting in an imbalance of resources. When employees lack resources to deal with the additional work required, emotional exhaustion will inevitably occur. At this time, employees are not willing to try to change the status quo of the organization at the risk of losing more resources. On the contrary, in order to avoid further loss of emotional resources, they often choose to escape to reduce psychological pressure. Bolton et al. confirmed that when an individual is in a state of emotional resource exhaustion, the level of psychological and emotional withdrawal will significantly increase [15]. Remaining silent in the workplace, as a typical exit strategy, has also become a relatively safe way for employees to save remaining resources and relieve psychological discomfort when they feel emotionally drained. 


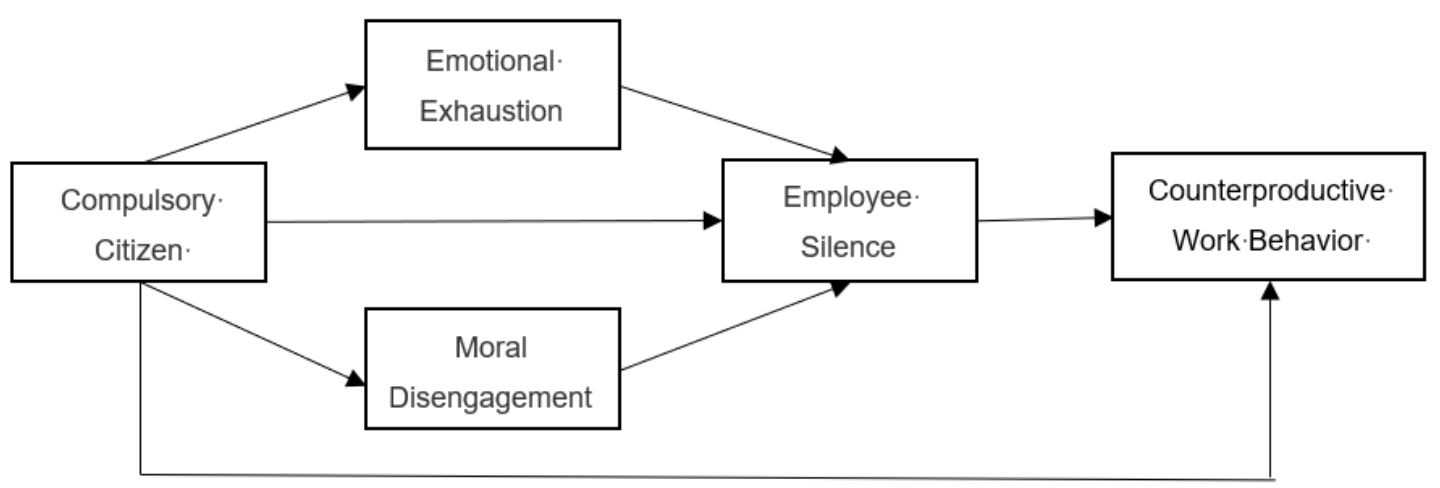

Figure 1: Theoretical model of this study

Bandura first proposed the concept of moral disengagement, which refers to a specific cognitive tendency generated by individuals in their behaviors. This cognitive tendency will allow individuals to redefine their behaviors and minimize their responsibility for the consequences of their behaviors, so that they can get rid of the guilt and remorse caused by violating moral standards [16].Bandura et al. developed the theory of moral disengagement on the basis of social cognition [17].According to this theory, moral disengagement inhibits an individual's moral regulatory system through eight mechanisms (moral justification, euphemism, glossing over comparison, buck-passing, distraction of responsibility, neglect/misinterpretation of results, dehumanization, and attribution of responsibility).At the same time, the level of moral disengagement has the characteristics of instability and will change with the change of organizational environment. The latest research of Fida et al. further shows that in organizations with heavy workload, more constraints, serious interpersonal conflict and lack of organizational support, employees are more likely to have negative emotions, promote more moral disengagement, and exhibit more unethical behaviors [18].Employees with high levels of job stress also tended to report relatively high levels of ethical disengagement and perceived unethical behavior as an ideal coping strategy. Thus, moral disengagement plays an important role in the relationship between job stress and unethical behavior. When employees are forced to engage in compulsory citizenship behavior, they will have negative emotions due to involuntarily engaging in work beyond the scope of duty. These negative emotions will lead to a decline in the level of moral self-regulation and become the reason and excuse for engaging in immoral behavior. The transformation from voice behavior to silence represents intentional concealment to some extent, which may be due to the decline of moral self-regulation level and the improvement of moral disengagement level of employees. Therefore, deliberate concealment will not bring guilt and remorse to employees. This study believes that compulsory citizenship will blur the personal ethics of employees and enhance the level of moral disengagement, which will be expressed through silence. Therefore, the following hypotheses are made in this study:

Hypothesis 3: Emotional exhaustion plays a mediating role between compulsory citizenship behavior and employee silence.
Hypothesis 4: Moral disengagement plays a mediating role between compulsory citizenship behavior and employee silence.

Combined with the above discussion, the following hypothesis model is proposed in this study (Figure 1):

\section{METHOD}

\subsection{Sample and Procedure}

In this research, the questionnaire method was adopted for data collection, and the employees of a large manufacturing enterprise were selected as the objects of investigation. A total of 647 questionnaires were collected, and the questionnaires completed in a very short time were regarded as invalid questionnaires. A total of 122 questionnaires were removed, and 525 valid questionnaires were obtained, with an effective rate of $81.14 \%$. Among them, males accounted for $76 \%$ and females accounted for $24 \%$; the mean age of the sample was 27.35 years old. Technical secondary school/high school or below accounted for $85.14 \%$, junior college accounted for $11.43 \%$, bachelor's degree accounted for $3.24 \%$; Master degree or above accounted for $0.19 \%$; In terms of length of service, $79.43 \%$ of workers have less than 1 year, $8.38 \%$ have $1-3$ years, $2.1 \%$ have $3-5$ years, $4.57 \%$ have $5-10$ years, and $5.52 \%$ have more than 10 years. In terms of positions, ordinary employees account for $91.81 \%$, grassroots managers account for $7.24 \%$, middle managers account for $0.57 \%$ and senior managers account for $0.38 \%$.

\subsection{Measures}

In order to ensure the validity of the study, the mature scale widely used by scholars at home and abroad was adopted in this research. Likert 5-point scale was used for all questionnaire measurements, in which 1 means "very inconsistent" and 5 means "very consistent".

Compulsory citizenship behavior. The compulsory citizenship behavior scale prepared by Eran Vigoda-Gadot [3] was adopted, consisting of 5 items. Management puts pressure on employees to perform additional work activities that go beyond their formal job duties. The internal consistency coefficient $\alpha$ of the scale was 0.856 .

Emotional exhaustion. The Emotional Exhaustion Scale developed by Watkins [19] was adopted, consisting of 3 items. I feel emotionally drained by my work. The internal consistency coefficient $\alpha$ of the scale was 0.885 . 
Table 1: Results of confirmatory factor analysis of the measurement model $(\mathrm{N}=525)$

\begin{tabular}{lllllll}
\hline Measurement Models & Combined & X2/df & CFI & TLI & RMSEA & SRMR \\
\hline Five-factor & CCB, EE, MD, ES, CWB & 2.96 & 0.96 & 0.95 & 0.06 & 0.07 \\
Four-factor & CCB, EE, ES, MD, CWB & 7.95 & 0.84 & 0.81 & 0.12 & 0.09 \\
Three-factor & CCB, EE+ES+MD, CWB & 10.27 & 0.78 & 0.75 & 0.13 & 0.11 \\
Two-factor & CCB, EE, ES+MD, CWB & 10.93 & 0.77 & 0.73 & 0.14 & 0.11 \\
Two-factor & CCB, EE+ES, MD, CWB & 11.40 & 0.75 & 0.72 & 0.14 & 0.12 \\
One-factor & CCB+EE+ES+MD+CWB & 16.98 & 0.62 & 0.57 & 0.18 & 0.14 \\
\hline
\end{tabular}

CCB, Compulsory Citizenship Behavior; EE, Emotional Exhaustion; MD, Moral disengagement; ES, Employee Silence; CWB, Counterproductive Work Behavior; CFI; Comparative fit index; IFI, Incremental fit index; RMSEA, Root mean square error of approximation.

Employee Silence. A questionnaire on employee silence behavior prepared by Chinese scholar Zheng Xiaotao [20] was adopted, with a total of 12 items. For example, the leader has basically decided that his own opinion will not play a big role, so he does not say. The internal consistency coefficient $\alpha$ of the scale was 0.945 .

Moral disengagement. It adopts the Moral Disengagement Questionnaire jointly developed by Bazerman et al. [21], with a total of 6 items. In some cases, being proactive and not playing by the rules is more important than the rules. The internal consistency coefficient $\alpha$ of the scale was 0.857 .

Counterproductive Work Behavior. The counterproductive behavior scale jointly developed by Dalal and Lam et al. was adopted [22], consisting of 12 items, including interpersonal counterproductive behavior and organizational counterproductive behavior. The interpersonal counterproductive behavior example is "I was impatient with my boss and colleagues", and the organizational counterproductive behavior example is "I was not doing my best work". The internal consistency coefficient $\alpha$ of the scale was 0.939 .

\section{RESULTS}

\subsection{Handling Common Variance Bias}

In this research, the responses to the questionnaire items have been obtained from a single source and both the dependent and focal explanatory variables are perceptual measures derived from the same respondent. This may result in common method variance. Common method variance is the variance that is attributable to the measurement method rather than to the constructs the measures represent [23]. We performed a one factor Herman test by loading all the items on to a single factor. Factor analysis indicated that this single factor could explain only $29 \%$ of the total variance. Podsakoff et al. indicate that there is no agreed cut-off point but a value of less than $50 \%$ is considered to be a reasonable value to indicate the reduced effect of common method variance [23]. Since in this research only $41.93 \%$ of the total variance is explained by a common factor, we can argue that effect of common method variance is limited.

\subsection{Confirmatory Factor Analysis (CFA)}

In order to test the discriminative validity of the measured variables, confirmatory factor analysis was conducted on five latent variables, namely compulsory citizenship behavior, emotional exhaustion, moral disengagement, employee silence, and counterproductive behavior (see Table 1).As can be seen from Table 1, the comparison of the five models shows that the five-factor model has the most ideal fitting effect $\left(\mathrm{X}^{2} / \mathrm{DF}=2.963, \mathrm{CFI}=0.959\right.$, TLI $=0.947$, $\mathrm{RMSEA}=0.061$, $S R M R=0.074$ ), which is significantly better than other factor models, indicating that the measurement variables in this study have achieved good discriminative validity.

\subsection{Descriptive Statistics}

The results of descriptive statistics and correlation analysis (see Table 2) showed that mandatory citizenship behavior, emotional exhaustion, moral disengagement, employee silence and counterproductive behavior were significantly positively correlated with each other.

\subsection{Hypothesis Tests}

Based on previous studies and correlation analysis among variables, this study uses AMOS to draw a structural equation model (Fig. 2) to investigate the main effect between compulsory citizenship and counterproductive behavior, as well as the mediating effect of emotional exhaustion, moral disengagement, and employee silence on compulsory citizenship and counterproductive behavior. The results show that the fitting index of this model is $\mathrm{X}^{2} / \mathrm{DF}=4.046$, $\mathrm{NFI}=0.91, \mathrm{CFI}=0.93, \mathrm{IFI}=0.93, \mathrm{RMSEA}=0.08$. The results showed that compulsory citizenship behavior had a significant positive effect on counterproductive behavior $(b=0.24, p<0.001)$, and hypothesis H1 was verified. Compulsory citizenship behavior positive effect on emotional exhaustion $(b=0.68, \mathrm{p}<0.001)$, in the role of compulsory citizenship behavior is moral protector $(b=0.45, \mathrm{p}<0.001)$, emotional exhaustion positive effect on employee silence $(b=0.40$, $\mathrm{p}<0.001$ ), moral evade a positive effect on employee silence (b $=0.44, \mathrm{p}<0.001)$, the staff silence positive role in the production behavior $(b=0.32, p<0.001)$.

$\mathrm{CCB}$, Compulsory citizenship behavior; EE, Emotional Exhaustion; $\mathrm{MD}$, moral disengagement; ES, employee silence, CWB, Counterproductive Work Behavior.

Based on the good fitting of the above models, the Bootstrap program of AMOS was used to repeat the sample for 5000 times, and the $95 \%$ confidence interval was calculated to test the significance of mediating effect. The specific results are shown in Table 3. The results show that the $95 \%$ confidence interval corresponding to the mediation path does not include 0 , indicating that the multiple mediation model of emotional exhaustion, moral disengagement 
Table 2: Means, standard deviations and intercorrelations of study variables $(\mathrm{N}=525)$

\begin{tabular}{|c|c|c|c|c|c|c|c|}
\hline & M & SD & $\mathrm{CCB}$ & $\mathrm{EE}$ & $\mathrm{MD}$ & ES & CWB \\
\hline $\mathrm{CCB}$ & 4.59 & 1.40 & .55 & & & & \\
\hline $\mathrm{EE}$ & 3.01 & 1.09 & $.67^{* *}$ & .73 & & & \\
\hline $\mathrm{MD}$ & 2.56 & 0.80 & $.45^{* *}$ & $.45^{* *}$ & .51 & & \\
\hline ES & 2.78 & 0.86 & $.63^{* *}$ & $.71^{* *}$ & $.65^{* *}$ & .73 & \\
\hline CWB & 2.28 & 0.78 & $.43^{* *}$ & $.42^{* *}$ & $.70^{* *}$ & $.62^{* *}$ & 0.88 \\
\hline
\end{tabular}

M, Mean; SD, Standard deviations; CCB, Compulsory citizenship behavior; EE, Emotional exhaustion MD, Moral disengagement; ES, Employee silence; CWB, Counterproductive work behavior; ${ }^{* *} \mathrm{p}<0.01$ (two tail test)



Figure 2: Structural equation model with parameter estimates

Table 3: Results of the analyses for multiple mediation (without covariates)

\begin{tabular}{|c|c|c|c|c|c|c|}
\hline \multirow{2}{*}{ PATH } & \multirow{2}{*}{ Indirect Effect ratio } & \multirow[t]{2}{*}{ SE } & \multicolumn{2}{|c|}{ Bias-corrected 95\%CI } & \multicolumn{2}{|c|}{ Percentile $95 \% \mathrm{CI}$} \\
\hline & & & Low Limit & High limit & Low Limit & High Limit \\
\hline CCB-ES-CWB & 0.07 & 0.04 & 0.02 & 0.17 & 0.01 & 0.15 \\
\hline CCB-EE-ES & 0.28 & 0.05 & 0.19 & 0.38 & 0.18 & 0.37 \\
\hline CCB-MD-ES & 0.20 & 0.04 & 0.13 & 0.29 & 0.12 & 0.28 \\
\hline CCB-EE-ES-CWB & 0.22 & 0.03 & 0.17 & 0.29 & 0.16 & 0.28 \\
\hline CCB-MD-ES-CWB & 0.14 & 0.03 & 0.07 & 0.26 & 0.06 & 0.25 \\
\hline Total indirect effect & 0.46 & 0.03 & 0.35 & 0.47 & 0.25 & 0.47 \\
\hline
\end{tabular}

CCB, Compulsory citizenship behavior; EE, Emotional Exhaustion; MD, Moral disengagement; ES, Employee silence; CWB,

Counterproductive work behavior.

and employee silence between compulsory citizenship behavior and counterproductive behavior is valid, that is, hypothesis $\mathrm{H} 2, \mathrm{H} 3$ and $\mathrm{H} 4$ are verified.

\section{DISCUSSION}

Through a questionnaire survey of employees in manufacturing enterprises, the results show that :(1) Compulsory citizenship behavior can trigger counterproductive behavior;(2) employee silence plays a mediating role between compulsory citizenship behavior and counterproductive behavior;(3) Compulsory citizenship behavior leads to employee silence through the mediating role of emotional exhaustion and moral disengagement, and finally leads to counterproductive behavior through employee silence.

\subsection{Theoretical contribution}

First of all, this study verifies the relationship between compulsory citizenship behavior and counterproductive behavior proposed by Vigoda-Gadot. Most of the previous studies focused on the analysis of the antectant variables of compulsory citizenship behavior and the discussion of the relationship between organizational citizenship behavior and counterproductive behavior. However, empirical studies on the relationship between compulsory citizenship behavior and counterproductive behavior are still relatively lacking. 
Secondly, a dual-processing model based on "emotion-cognition" is proposed to explain the relationship between compulsory citizenship behavior and counterproductive behavior for the first time. This study is the first to integrate previous studies based on either emotional or cognitive processes.

Thirdly, it expands the research scope of employee silence. Previous important studies on employee silence mainly focus on the analysis of its antecedent variables and the division of its motivations and dimensions. However, this study takes employee silence as a mediating variable and examines its mediating role between compulsory citizenship behavior and counterproductive behavior.

\subsection{Practical implications}

First of all, as an organizational manager, we should pay attention to the distinction between compulsory citizenship behavior and organizational citizenship behavior, and understand its boundary. We should pay attention to and reduce compulsory citizenship behavior, cultivate positive and healthy organizational citizenship behavior, and avoid "good soldiers" to become "good actors", and eventually decay into "bad apples".

Secondly, this study shows that silence, as a key link in the whole process, cannot be ignored. It can be regarded as an early warning signal in the process of "good actors" turning into "bad apples". Organizations should create a harmonious and effective communication atmosphere to minimize employee silence.

Thirdly, organizational managers should provide sufficient working resources (such as work autonomy, decision-making right, etc.), provide more support and timely psychological assistance to avoid the occurrence of emotional exhaustion of employees.

\subsection{Limitations and future research}

There are also research limitations in this study. First, the study was based on cross-sectional data collection and analysis, and no causal relationship could be determined. Second, this study is limited to manufacturing employees, and future studies can be conducted across industries to determine the universality of the model. Employee silence which are mentioned in the third, this study is regarded as the concept of dimensions of a single, but in fact silence can according to different motives are divided into different dimensions, future research can expand the research model, such as further extend from the silence of the multiple dimension inspection production in compulsory citizenship behavior and the behavior between the role.

\section{REFERENCES}

[1] Bies, R.J. and D.W. Organ, Organizational Citizenship Behavior: The Good Soldier Syndrome. The Academy of Management Review, 1989. 14(2): p. 294.
[2] VIGODA GADOT, E., Compulsory Citizenship Behavior: Theorizing Some Dark Sides of the Good Soldier Syndrome in Organizations. Journal for the theory of social behaviour, 2006. 36(1): p. 77-93.

[3] Vigoda-Gadot, E., Redrawing the boundaries of OCB? An empirical examination of compulsory extra-role behavior in the workplace. Journal of Business and Psychology, 2007. 21(3): p. 377-405.

[4] Spector, P.E., et al., The dimensionality of counterproductivity: Are all counterproductive behaviors created equal? Journal of Vocational Behavior, 2006. 68(3): p. $446-460$.

[5] Bennett, R.J. and S.L. Robinson, Development of a measure of workplace deviance. J Appl Psychol, 2000. 85(3): p. 349-360.

[6] Ahmadian, S., H. Sesen and S. Soran, Expanding the boundaries of compulsory citizenship behavior: Its impact on some organizational outputs. Business and Economic Horizons, 2017. 13(1): p. 110-118.

[7] Fox, S., P.E. Spector and D. Miles, Counterproductive Work Behavior (CWB) in Response to Job Stressors and Organizational Justice: Some Mediator and Moderator Tests for Autonomy and Emotions. Journal of vocational behavior, 2001. 59(3): p. 291-309.

[8] Bolino, M.C., W.H. Turnley and B.P. Niehoff, The other side of the story: Reexamining prevailing assumptions about organizational citizenship behavior. Human resource management review, 2004. 14(2): p. 229-246.

[9] Yam, K.C., et al., From Good Soldiers to Psychologically Entitled: Examining When and Why Citizenship Behavior Leads to Deviance. Academy of Management journal, 2017. 60(1): p. 373-396.

[10] Bashir, M., et al., The Mediating Role of Psychological Need Thwarting in the Relationship Between Compulsory Citizenship Behavior and Psychological Withdrawal. Frontiers in Psychology, 2019. 10.

[11] He, P., et al., Compulsory Citizenship Behavior and Employee Silence: The Roles of Emotional Exhaustion and Organizational Identification. Social Behavior and Personality: an international journal, 2018. 46(12): p. 2025-2047.

[12] He, P., et al., How and When Compulsory Citizenship Behavior Leads to Employee Silence: A Moderated Mediation Model Based on Moral Disengagement and Supervisor-Subordinate Guanxi Views. Journal of Business Ethics, 2019. 155(1): p. 259-274.

[13] Maslach, C., W.B. Schaufeli and M.P. Leiter, Job burnout. Annu Rev Psychol, 2001. 52: p. 397-422.

[14] Jahanzeb, S. and T. Fatima, How Workplace Ostracism Influences Interpersonal Deviance: The Mediating Role of Defensive Silence and Emotional Exhaustion. Journal of Business and Psychology, 2018. 33(6): p. 779-791.

[15] Bolton, L., et al., Counterproductive Work Behaviours in Response to Emotional Exhaustion: A Moderated Mediational Approach. Stress and Health, 2012. 28(3): p. 222-233.

[16] Bandura, A., Social foundations of thought and action: A social cognitive theory. Journal of Applied Psychology, 1986. 12(1): p. 169.

[17] Bandura and Albert, Selective Moral Disengagement in the Exercise of Moral Agency. Journal of Moral Education, 2002. 31(2): p. 101-119.

[18] Paciello, M., et al., Stability and Change of Moral Disengagement and Its Impact on Aggression and Violence in Late Adolescence. Child Development, 2008. 79(5): p. 1288-1309.

[19] Watkins, M.B., et al., Compassion organizing: Employees' satisfaction with corporate philanthropic disaster response and reduced job strain. Journal of Occupational and Organizational Psychology, 2015. 88(2): p. 436-458.

[20] Zheng, X.T., Survey on Employee Silence and the Impact of Trust on it in China. Acta Psychologica Sinica, 2008. 40(2): p. 219-227.

[21] Shu, L.L., F. Gino and M.H. Bazerman, Dishonest Deed, Clear Conscience: When Cheating Leads to Moral Disengagement and Motivated Forgetting. Personality and Social Psychology Bulletin, 2011. 37(3): p. 330-349.

[22] Dr, S., et al., A Within-Person Approach to Work Behavior and Performance: Concurrent and Lagged Citizenship-Counterproductivity Associations, and Dynamic Relationships with Affect and Overall Job Performance. Academy of Management Journal, 2009.

[23] Podsakoff, P.M., et al., Common method biases in behavioral research: A critical review of the literature and recommended remedies. Journal of Applied Psychology, 2003. 88(5): p. 879-903. 